\title{
Análise das tendências de aplicação do conceito de periurbano
}

\section{Análisis de las tendencias de aplicación del concepto periurbano}

\section{Analysis of trends in the application of the concept of peri-urban}

\author{
Augusto dos Santos Pereira \\ augustogeog@gmail.com \\ Universidade Federal do Paraná
}

Resumo: Com vista a compreender a contribuição do conceito de periurbano para o planejamento urbano-regional, o trabalho mostra ampla revisão do estado da arte das discussões sobre o tema. Demonstra que a periurbanização tem sua raiz na década de 1940, no conceito de urban fringes, e que se disseminou pelo mundo, podendo ser identificado hoje em países ricos ou pobres. A aplicação do conceito de periurbanização para contextos diferentes na Ásia, África e Europa exige um esforço de sintetizar o que há de comum em seu uso. Independentemente do contexto específico em que o processo se dá, é possível observar a presença de três elementos fundamentais: o papel de intermediação dessas áreas em relação aos fluxos urbano-rurais; suas características transicionais; além de conflitos e oportunidades concernentes a essas áreas ensejados por suas características distintas.

Palavras-chave: Periurbanização. Áreas Periurbanas. Franjas Urbanas. Relações Urbano-Rurais.

Resumen: Teniendo en vista comprender la contribución del concepto de periurbano para la planificación urbana e regional, este trabajo muestra una amplia revisión del estado del arte de discusiones sobre el tema. Muestra que la periurbanización tiene su raíz en la década de 1940, en el concepto de urban fringes, y que se disemino por el mundo, lo que permite que sea identificado hoy en países ricos y pobres. La aplicación del concepto de periurbanización para contextos diferentes en Asia, África y Europa exige un esfuerzo de sintetizar lo que hay de común en su uso. Independiente del contexto específico en que se da el proceso, es posible observar tres elementos fundamentales: el papel de intermediación de estas áreas en relación a los flujos urbano-rurales; sus características transicionales; y los conflictos y oportunidades alusivos a estas áreas ocasionados por sus características distintas.

Palabras-claves: Periurbanización. Áreas periurbanas. franjas urbanas. relaciones urbano-rurales.

Abstract: Aiming to comprehend the contribution of the concept of peri-urban to the
regional-urban planning, this paper shows a broad review of the state of the art of
the discussions about the issue. It demonstrates that peri-urbanization has its origin
in the 1940s, with the urban fringes concept, and it spread all over the world, being
identifiable in both rich and poor countries. Applying the peri-urbanization concept
onto different contexts in Asia, Africa and Europe demands an effort to synthesize what
is common in its usage. Regardless of the specific context where the process unfolds, it
is possible to observe the presence of three fundamental elements: the intermediation 
role that these areas have amid the urban-rural fluxes; its transitional features; conflicts and opportunities that are particularly linked to these kinds of areas brought about by its distinct characteristics.

Keywords: Periurbanization. Peri-urban areas. Urban fringes. Urban-rural relations.

\section{INTRODUÇÃO}

O presente trabalho apresenta resultados da pesquisa em andamento em nível de mestrado em desenvolvimento no Programa de Pós-Graduação de Geografia da UFPR. A dissertação em desenvolvimento visa à averiguação da pertinência do conceito para o planejamento da Região Metropolitana de Curitiba - RMC. Para tanto, estabeleceu-se como um dos objetivos um levantamento da pesquisa sobre a temática, tendo em vista a necessidade de uma melhor caracterização do conceito de periurbano para observar quais podem ser suas contribuições ao planejamento urbano-regional e metropolitano no Brasil.

Considerando-se que a literatura sobre o assunto ainda é pequena no Brasil, procedeu-se a uma investigação não somente na bibliografia nacional, mas também na oriunda de diversas partes do mundo. O resultado, portanto, apresenta uma síntese daquilo que seja marcadamente comum à literatura em cenários bastante distintos, seja na África, Ásia, Europa ou Américas, obviamente dando-se espaço para as diferenças do processo nesses contextos díspares.

Isso posto, o texto está divido em três itens principais. No primeiro é apresentado um breve histórico da pesquisa, ao passo que no segundo se demonstra a generalização da periurbanização ao redor do mundo. O terceiro, intitulado "Aspectos relevantes da periurbanização", é dividido em três subitens - intermediação, transição, conflito e oportunidade - que sintetizam os elementos mais comuns sobre a temática a partir de estudos versados em áreas tão distintas.

\section{HISTÓRICO}

A construção da noção de periurbanização tem sua raiz no termo urban fringes, cunhado por geógrafos norte-americanos a partir do estudo que descreviam mudanças populacionais no estado de Louisiana, nos Estados Unidos. Esse termo foi bastante utilizado na pesquisa durante as décadas de 1940 e 1950 nos EUA. Nesse momento o foco se encontrava sobre os espaços onde o crescimento suburbano toma lugar, gerando áreas nas quais os usos da terra urbanos e rurais se encontravam misturados. (ADELL, 1999, p. 5).

Quando comparadas com os EUA, algumas condições favoráveis para a formação de áreas suburbanas mais longínquas em relação ao centro, tais como a generalização do automóvel, ou mesmo a prosperidade necessária para a aquisição de produtos imobi- 
liários unifamiliares, teriam sido retardadas na Europa. Isso em especial por condições ensejadas pelo período entreguerras e o pelo intervalo necessário à recomposição econômica europeia no pós-guerra.

Steinberg (2003) identifica que as condições para a formação de áreas periurbanas propriamente ditas na Europa teriam se dado a partir do final da década de 1960. No caso francês, as condições de surgimento do fenômeno teriam sido: o papel do mercado imobiliário formal com novos empreendimentos para as classes abastadas em busca de amenidades; generalização do uso do automóvel; programas imobiliários destinados às classes mais baixas realizados em áreas de bordas das cidades, tendo em vista os menores preços dos terrenos; construção de estruturas viárias permitindo o espraiamento dos loteamentos.

Steinberg reconhece a emergência de áreas mistas na Rússia, Inglaterra, países nórdicos, acreditando que na Europa, Itália e Espanha ainda contariam com cidades mais compactas. Para ele, não haveria correspondência nos países emergentes ao que se chama de periurbanização na França. O crescimento das periferias planificadas ou informais, favelas ou barriadas, incorporariam mais uma extensão sem fim das cidades e metrópoles, do que urbanizações realmente descontínuas (STEINBERG, 2003, p. 77).

Para MacGregor et al. (2006, p. 7), no entanto, certos fenômenos que envolvem os países do sul precisam ser levados em consideração, na medida em que são catalisadores do processo de periurbanização fora de seu eixo original, nos Estados Unidos e na Europa. Os autores tratam em especial da mudança na divisão internacional do trabalho. Esse processo estaria ocorrendo de forma a promover a rápida industrialização de inúmeros países acompanhada pelo crescimento da renda de certos grupos e pelo empobrecimento de outros. A relação entre os novos modelos produtivos, o crescimento da renda de classes abastadas e a aglomeração de grandes contingentes empobrecidos seriam fatores de atração para as áreas de borda das cidades, no limite com as áreas rurais, seja de empresas, condomínios, estruturas viárias para o atendimento das novas localizações e escoamento produtivo etc. Dessa forma, estariam se dando em largas proporções, nos países pobres e em desenvolvimento, as condições para a formação de áreas periurbanas, se não de acordo com o modelo francês, mas bastante diferente do subúrbio compacto.

Essa pressuposição de que a noção de periurbanização é relevante e que há fora do circuito dos países ricos condições para a sua manifestação levou ao surgimento de medidas para o fomento à pesquisa. São exemplos a formação do Peri-urban Research Project Team, da Universidade de Londres, financiado pelo Department for International Development do Reino Unido, cujo principal esforço era reunir informações sobre o desenvolvimento de áreas periurbanas em países em desenvolvimento entre 1995 e 2005.

No Brasil, um dos primeiros trabalhos sobre áreas periurbanas foi o realizado por Juillard (1961, apud CORRÊA, 1986), comparando os processos imobiliários e produtivos do entorno urbano de Salvador com cidades europeias. Para o autor, na Europa o processo de urbanização ocorria então paulatinamente, e a agricultura periurbana chegaria a conviver durante certo tempo com a urbanização, ao passo que no Brasil 
[...] uma tradição especulativa vinculada aos produtos tropicais leva à passagem direta da agricultura especulativa para a especulação da terra, transformando a periferia, logo após o espaço urbano contínuo, em um “deserto agrícola”, à espera de loteamentos que podem demorar anos e anos a serem implantados. (CORRÊA, 1986, p. 72).

É possível que o crescimento demográfico urbano acelerado e a prática de transformação do solo rural em urbano de forma predatória, conforme verificado por Juillard e por Corrêa, estejam relacionados com o desinteresse sobre o tema de periurbanização no Brasil, quiçá com a sua inaplicabilidade nas décadas em que se experienciou um grande êxodo rural.

Observa-se que o próprio Corrêa, ao mencionar o termo periurbano, o fazia associando-o a um processo de formação de áreas urbanas. Para o autor:

No século XX, com a expansão urbana, sobretudo com o processo de metropolizacão, a transformação do campo periurbano, originando primeiramente uma periferia rural-urbana e, após, subúrbios integrados ao espaço urbano, adquiriu enorme magnitude. (CORRÊA, 1986, p. 71)

Isso mostra como esse termo foi secundário, sendo parte do processo explicativo das estratégias dos atores imobiliários na formação do espaço urbano. Entendemos que esse processo de rápida transformação e de esterilização do solo (CORRÊA, 1986; e JUILLARD, 1961, apud CORRÊA, 1986) pode não ter dado lugar à plurifuncionalidade necessária à formação de espaços periurbanos, justificando o desinteresse dos pesquisadores brasileiros na aplicação do conceito.

A partir de meados da década de 1990 começa a se notar uma mudança sobre a questão da separação entre o urbano e o rural no Brasil. Milton Santos (1993, p. 65) aborda o tema de regiões agrícolas que contêm cidades e regiões urbanas que contêm atividades agrícolas.

É também na década de 1990 que o Projeto Rurbano procura apresenta “o novo rural brasileiro", um diagnóstico das mudanças nas áreas rurais de 1985 a 1996. Esse projeto traz mais atenção para várias questões novas à ruralidade, entre elas uma que é de longa data do interesse da pesquisa em áreas periurbanas, a plurifuncionalidade, então abordada a partir das ocupações rurais não-agrícolas (ORNAS).

Outros trabalhos são exemplo das novas abordagens que requerem a releitura do papel das áreas rurais no Brasil e da relação entre urbano e rural. Ricardo Abramovay (2000) demonstra que as medidas que delimitam as áreas rurais por vezes tendenciam o olhar de forma a que não seja notado o papel fundamental da ruralidade no desenvolvimento.

No mesmo sentido José Eli da Veiga (2002) publica um livro e uma série de artigos nos quais afirma que os cálculos da dimensão rural do Brasil são realizados com base no Decreto-Lei 311 de 1938. Após décadas em que o rural vinha sendo visto como o lugar do atraso, um dos velhos mitos do rural brasileiro (SILVA, 2001), o território de onde milhões de brasileiros partiam em busca de melhores condições de vida nas áreas urbanas, esses e outros trabalhos vinham representar uma revalorização das áreas rurais. 
É nesse contexto de revalorização do rural que se encontra o período no qual se nota um novo crescimento do interesse sobre as relações urbano-rurais - vide o livro Cidade e campo: relações e contradições entre urbano e rural, organizado por Sposito e Whitacker (2006) -, bem como o da pesquisa em áreas periurbanas no Brasil, como parte integrante desse movimento versado nas relações campo-cidade.

Nesse ínterim, é publicada a tese de Lívia Izabel Bezerra Miranda (2008), que contribui significativamente para a concepção da gestão dessas áreas ao demonstrar a necessidade e aplicabilidade das ferramentas de gestão urbano-regionais existentes no Brasil. Outra tese tratando do assunto é a de Ana Rute do Vale (2005), texto que aborda a plurifuncionalidade periurbana no entorno da cidade paulista de Araraquara, com especial atenção ao turismo rural.

Com suporte financeiro do Department for International Development (DFID) do Reino Unido, entre 1999 e 2006, o Núcleo de Estudos Urbanos e Regionais da Universidade de Brasília encabeçou o projeto Discussões Metodológicas e Aplicação do Zoneamento Ecológico-Econômico em Áreas Urbanas, buscando inserir o espaço urbano como parte da totalidade regional no planejamento, sem ignorar as áreas de borda.

Desde 2009 encontra-se em funcionamento o Laboratório de Estudos Periurbanos (Lepur), na Universidade Federal de Pernambuco, sob coordenação de Maria de Fátima Furtado e Ricardo Furtado. Sob a coordenação de Rainer Randolph, o Laboratório Oficina Redes e espaço (Labore) vem trabalhando uma adaptação do conceito de periurbanização, a perimetropolização, aplicando-a ao estudo das dinâmicas ligadas à segunda residência nas áreas periféricas da Região Metropolitana do Rio de Janeiro. (RANDOLPH, 2007)

Em 2009, o LABORE, juntamente com o Instituto de Pesquisa e Planejamento Urbano e Regional (Ippur), da Universidade Federal do Rio de Janeiro, realizou o Seminário Internacional A Expansão da Metrópole para além das Fronteiras de sua Região, no qual, entre os temas privilegiados, encontravam-se: “Expansão da Metrópole, periferias expandidas, franja e transformações urbano-rurais" e "A interface urbana-regional e urbana-rural em torno das metrópoles - experiências brasileiras" (LABORE, 2009, p. 8).

Como se pode verificar, não é de hoje o interesse dos pesquisadores sobre áreas periurbanas, ainda que aplicando termos correlatos. De fato essa pesquisa tem crescido em vários países, inclusive no Brasil. Entendemos que o crescimento dessa abordagem reflete a necessidade verificada no meio acadêmico de se compreender as dinâmicas particulares dessas áreas, as suas tendências e interação nas parcelas e todo regional.

\section{PERIURBANIZAÇÃO, PROCESSO GLOBAL}

O conceito de periurbanização se encontra bastante difundido. McGregor et al. (2006, p. 5) mostram que ele está agora bem estabelecido em língua inglesa como "periurban", sendo expresso em holandês como halfstedig (semi-urbano), em alemão como urban-ländlichenz zonen (zonas urbano-rurais) e em africâner buitestedelik (cidade externa, 
ou além da cidade). Em francês, Jean Steinberg (2003, p. 75) usa o termo périurbanisation, enquanto Margarida Pereira (2008, p. 113) prefere espaços periurbanos. Lívia Miranda (2008) aplica em seu estudo sobre a Região Metropolitana de Recife o termo áreas de transição rural-urbana. Entre os órgãos oficiais de pesquisa estatística que aplicam o conceito, destaca-se o Institut Nacional de las Statistiques et des Études Économiques (INSEE, 2009), na França, adotando em algumas de suas pesquisas o termo couronnes périurbaines (coroas periurbanas). No próprio trabalho de McGregor et al. (2006), no entanto, há uma opção pelo termo peri-urban interface (PUI), buscando salientar a sua posição como espaço de contato, como interface onde convivem aspectos urbanos e rurais.

De maneira geral, áreas periurbanas são concebidas como espaços de transição. Áreas em que coexistem lógicas urbanas e rurais, criando espaços com atributos específicos, fragilidades e potencialidades próprias, resultantes das interações dos elementos urbanos e rurais. Sua transição se destaca do ponto de vista paisagístico, socioeconômico e ambiental.

O sentido do que se compreende por periurbano é variável segundo cada autor. Steinberg (2003), estudando o processo de surgimento e evolução das áreas periurbanas na França, caracteriza-as pelo aspecto híbrido de suas paisagens, com descontinuidades urbanas em meio a áreas ruralizadas no entorno das cidades. Para ele a periurbanização seria:

[...] extensão cada vez mais marcada das aglomerações urbanas, não tanto sob a forma de uma 'mancha de óleo' contínua, mas, sobretudo, como uma 'pele de leopardo', na qual os organismos do tipo urbano se disseminam em um meio rural mais ou menos preservado. (STEINBERG, 2003, p. 76)

Versando sua pesquisa em Lisboa, Margarida Pereira (2004), em crítica ao processo espraiamento das cidades europeias, caracteriza as interfaces com base em sua "organização caótica" (PEREIRA, 2004). Segundo a autora, nesses espaços se encontram conjuntamente:

áreas habitacionais desqualificadas, com standards urbanísticos e de habitação muito abaixo do aceitável; produtos imobiliários de elevado standing e por vezes inovadores (condomínios habitacionais privados, parques tecnológicos e de escritórios, centros comerciais nas suas diversas configurações, parques temáticos, campos de golfe). (PEREIRA et al., 2008, p. 111)

A partir de síntese dos resultados do Peri-Urban Environmental Change Project (PU-ECH), sob os auspícios do Scientific Committee on Problems of the Environment (Scope), com base em dados sobre Líbano, Argentina, Gana, Jordânia, Zimbábue, Índia, entre outros países, Ian Douglas (2006) acrescenta à Peri-urban interface seu caráter transitório, sujeito a mudanças aceleradas, bem como o limbo institucional em que, geralmente, se encontram. Essa interface seria:

[...] a zona transicional, ou zona de interação, onde atividades urbanas e rurais estão justapostas, e características da paisagem estão sujeitas a rápida mudança, levando a transformações nos sistemas hidrológico, ecológico, geomorfológico e socioeconô- 
mico, sendo frequentemente negligenciadas tanto pelas administrações rurais como urbanas. (DOUGLAS, 2006, p. 18)

Há uma recorrência de aspectos semelhantes sobre aquilo que se tem convencionado chamar de periurbano em diversas partes do mundo. Entre essas particularidades estão: rápida alteração; difusão de elementos urbanos cercados por paisagens rurais; preferência pela instalação de grandes equipamentos urbanos (aeroportos, shoppings, parques industriais, grandes condomínios); atratividade para estabelecimento de moradias de classes solváveis, por conta das amenidades, e, ao mesmo tempo, de classes pobres, por conta dos baixos preços dos terrenos, ou maior presença de um mercado informal; conformação de riscos socioambientais próprios a partir da singularidade propiciada pela interação de elementos urbanos e rurais justapostos.

A forma como esses elementos têm sido repetidamente aventados em estudos sobre cidades europeias, asiáticas, africanas e americanas levanta um ponto fundamental, a saber: a periurbanização seria hoje uma tendência global.

Considerar a tendência global, apesar da temeridade da noção, não ignora aspectos regionais e locais. Trata-se de compreender que certos elementos bastante difundidos no mundo moderno, seja em países pobres, seja em países ricos, influenciam a conformação de áreas de transição entre o urbano e o rural, sem perder de vista as especificidades regionais.

De maneira geral, verifica-se que os estudos que versam sobre as condições para o surgimento de áreas periurbanas em países europeus tratam do apogeu da residência unifamiliar - ainda que em condomínios fechados, da criação de produtos imobiliários pautados na "venda" de amenidades, da generalização do automóvel e de estruturas viárias e de transporte de grande capacidade voltadas para o interior das grandes cidades, além do policentrismo urbano engendrado pela possibilidade de realocação das atividades produtivas e de serviços a partir do uso de novas tecnologias de informação e de produção. Também nesses casos, os estudos apontam para a revalorização de certos serviços rurais próximos às aglomerações - chácaras para lazer e produção de itens agropecuários destinados diretamente para o varejo.

Os estudos sobre casos asiáticos apresentam certas semelhanças com os casos europeus, tais como o policentrismo, a generalização do automóvel e outras formas de transporte engendrando o espraiamento da cidade, entre outros fatores. Apontam, no entanto, para uma diferença significativa, o papel da periurbanização no contexto de grandes aglomerações urbanas. Assim, os trabalhos têm se dedicado à conformação de áreas periurbanas nos interstícios de cidades milionárias - Hubli-Dharward (Índia) e Calcutá (Índia), Bangkok (Tailândia), Guangzhou (China), Jacarta (Indonésia) etc. Nessas áreas, ainda conectadas às lógicas de transição demográfica urbano-rural, já superada na Europa há décadas, os fluxos migratórios que se fazem notar nas áreas periurbanas estão mais ligados às populações campesinas em busca de serviços urbanos. Na Europa, por sua vez, o fluxo está mais ligado às classes médias urbanas em busca de amenidades rurais. 
Na África, há várias pesquisas que apontam para o processo de formação de áreas periurbanas a partir da recepção de pobres oriundos de áreas rurais. Essas populações, cujas estratégias de subsistência seriam minadas no interior das cidades, ao se instalarem próximas a terras devolutas ao redor das cidades, passam ao cultivo vegetal em pequena escala, pastoreio ou coleta de lenha com vista à venda nos mercados próximos. Não se encontra uma tendência de policentrismo nas cidades africanas, como o evidenciado em outras partes do mundo.

$\mathrm{Na}$ América Latina, um panorama geral de processo ainda não pode ser realizado, mas o conjunto de trabalhos sobre temas diversos, tais como deslocamento populacional intraurbano, crescimento de condomínios fechados no rebordo metropolitano, agricultura urbana etc. apontam para a presença de elementos que se assemelham a aspectos europeus - policentrismo e dinamismo econômico -, africanos - grande presença de imigrantes oriundos de áreas rurais distantes em algumas cidades da América hispânica - e asiáticos - peculiaridades das cidades milionárias como São Paulo, Cidade do México e Rio de Janeiro.

De fato, esses grandes esquemas têm serventia didática, à medida que demonstram certas tendências que, em maior ou menor monta, são identificadas no processo de estabelecimento de áreas de transição urbano-rurais, mas é preciso se manter em mente os limites de tais generalizações.

$\mathrm{Na}$ África, tem-se, por exemplo, o entorno de Jos, cidade Nigeriana que, a partir de grandes estruturas deixadas pela mineração de estanho do início do século $\mathrm{XX}$, apresenta uma agricultura periurbana bastante rica e diversificada, com maior correspondência com aquelas praticadas nos entornos metropolitanos latinos e asiáticos, do que com as práticas de subsistência comuns às áreas de transição no próprio continente africano.

Vê-se que o conceito periurbano vem sendo utilizado internacionalmente na pesquisa, adaptado a diferentes contextos. Outro aspecto que sugere a internacionalização do fenômeno de periurbanização está ligado à valorização dos espaços periféricos ao redor do mundo. Trata-se de lugares onde o capital ainda não explorou completamente o seu potencial. Dessa forma, o aumento da rentabilidade com as commodities alimentícias dos países africanos e sul-americanos, o boom da industrialização dos países emergentes, mormente asiáticos, e os amplos mercados potenciais para uma cesta diversa de produtos nesses países bastante populosos têm atraído vultosos investimentos nos últimos anos.

Esse rearranjo econômico recente, por mais discutível que seja a amplitude de seus efeitos no peso político dos países pobres e em desenvolvimento no cenário global, inegavelmente leva para esses países a interferência capitalista necessária para a reestruturação territorial das grandes e médias cidades, lócus da organização da produção e do consumo de bens e serviços.

Isso implica resgatar a noção de MacGregor (2006) sobre os efeitos da nova divisão internacional do trabalho sobre os espaços regionais, ensejando condições necessárias para o desenvolvimento de áreas periurbanas, tais como: grandes estruturas para transporte de pessoas e mercadorias; aumento da renda de parte da população, possível 
compradora de automóveis e imóveis de segunda residência - fatores de surgimento de áreas periurbanas por excelência -, melhoria das redes de telecomunicações, permitindo a realocação de empresas para áreas mais distantes dos centros etc.

\section{ASPECTOS RELEVANTES DA PERIURBANIZAÇÃO}

Dado o recente crescimento do interesse acadêmico sobre o processo de periurbanização, que cria um cenário no qual o conceito de espaço periurbano é empregado para os mais diversos contextos, procedeu-se a uma sistematização daquilo que se mostrou mais comum ao longo da bibliografia: o papel de intermediação dessas áreas em relação aos fluxos urbano-rurais; suas características transicionais; conflitos e oportunidades concernentes a essas áreas ensejados por suas características distintas.

\section{INTERMEDIAÇÃO}

Entre os aspectos recorrentes e marcantes na pesquisa sobre as características dos espaços periurbanos se encontra a sua posição intermediária. Trata-se de considerar as áreas de transição urbano-rurais em posição regional ao redor das cidades, entre elas e a hinterlândia rural.

É importante salientar que essa posição entre a cidade e o campo traria mudanças qualitativas para uma série de fenômenos que se desenvolvem nos espaços periurbanos. É lá que se instalam as famílias urbanas de classes solváveis, de cidades economicamente pujantes, em busca de amenidades rurais, no entanto sem abrir mão dos serviços urbanos e da proximidade com o mercado de trabalho. Também é lá que se encontram terrenos mais baratos e com maior disponibilidade no mercado informal para - ou, ainda, para ocupação por - famílias de baixa renda.

Os amplos espaços próximos a pequenos centros secundários de estruturas urbanas policêntricas seriam fator de atração para investimentos destinados à instalação de grandes complexos empresariais. Atividades de lazer, vendendo os prazeres de ilhas de ruralidade, se utilizam dessa posição intermediária para atender à demanda das populações urbanas, tal como o fazem os "caminhos" ao redor da Região Metropolitana de Curitiba - Caminho do Vinho, em São José dos Pinhais, Caminho Italiano, em Colombo, Caminho do Guajuvira, em Araucária etc.

Assim sendo, a posição intermediária do espaço periurbano lhe confere um papel também de intermediação. A sua valoração pela posição entre o urbano e o rural seria também fator de mediação entre os fluxos e demandas em ambos os sentidos - do urbano para o rural, do rural para o urbano -, tanto de pessoas como de produtos.

Em vários estudos sobre periurbanização em países com grande processo de êxodo rural em curso, verifica-se que grandes contingentes não vão morar no núcleo urbano, onde lhes são exigidos uma renda muito maior que a disponível para poderem obter 
moradia, bem como melhor qualificação profissional para os trabalhos ali disponíveis. Nas áreas periurbanas desses países, essas populações recém-chegadas do campo, encontram, por vezes, terras do Estado para cultivo de pequenas culturas, ou coleta de madeira e outros para venda nos mercados urbanos próximos.

Na África, segundo McGregor et al. (2006), a intermediação periurbana se destaca à medida que populações tradicionais deixam o campo em direção às áreas urbanas, mas se instalam no seu entorno, de maneira espraiada, com o fim de se ocupar de horticultura, geralmente em terras do Estado, e coleta de lenha para comercialização nos centros urbanos como estratégia de sobrevivência.

Morale et al. (2002) estudam, na Região Metropolitana de Santiago do Chile, os fluxos intraurbanos gerados pela busca de amenidades rurais de entorno por parte das famílias de maior renda. Ressaltam a concentração na periferia de domicílios constituídos por migrantes intraurbanos cujos chefes de família estejam atuando em profissões tradicionalmente carregadas de status social e bem remuneradas - médicos, engenheiros, advogados, arquitetos etc.

A posição intermediária medeia também a relação de custos dos produtos agropecuários. Hortifrutigranjeiros ou outros produtos perecíveis - leite e queijo de produção rudimentar, por exemplo -, acabam consideravelmente encarecidos quando originados em grandes distâncias. Nesse sentido, tem sido comum a sua produção em áreas periurbanas. De fato, em certas partes do mundo onde tem havido o incentivo à agricultura urbana, o que se tem visto é um resultante incremento da agricultura periurbana (DOUGLAS, 2006).

Exemplo evidente dessa relação de custo se encontra em BHAT et al. (2006), abordando a produção de leite de búfalo nas cidades "gêmeas" de Hubli e Dharwad, na Índia. Nesse estudo, foi verificado que, seja para criadores não proprietários, seja para proprietários de terras de diferentes tamanhos, a proximidade da cidade aumentava tanto a quantidade de leite vendido como o valor recebido por litro de leite, mormente relacionado à disponibilidade de produto mais fresco, bem como de acesso aos mercados consumidores sem intermediários.

De maneira geral, o ganho com certas produções parece ser potencializado no entorno das cidades, corroborando para uma melhor qualidade de vida dos habitantes das áreas periurbanas, quando comparados com as populações das áreas rurais mais distantes, ainda que aplicadas ao mesmo tipo de produção agropecuária.

Allen (2006) mostra, ainda, que a posição intermediária das áreas periurbanas é o fator essencial para que essas sejam o destino do lixo urbano.

Na Região Metropolitana do Rio de Janeiro, Randolph (2007) tem adotado uma noção de intermediação para explicar a relação entre os municípios perimetropolitanos e o espaço ao redor da região metropolitana. Essa mediação não corresponde ao papel das cidades médias na hierarquia urbana, mas a um papel dos municípios intermediários, perimetropolitanos, em oferecer serviços de lazer e segunda residência aos moradores da metrópole, trazendo para os municípios mais distantes um maior dinamismo econômico. 


\section{TRANSIÇÃO}

Vistos os elementos enumerados acima, observa-se que atentar para a noção de intermediação em áreas periurbanas significa compreender a forma como esses espaços, por sua posição intermediária, acomodam preferencialmente, ou de forma diferenciada, certos fixos ligados aos fluxos urbano-rurais. Do imbricado acondicionamento de habitações para pessoas de diferentes classes - pobres vindos do campo e da cidade, e pessoas de maior renda em busca de amenidades -, de grandes empreendimentos, de propriedades agropecuárias e destinadas ao lazer rural, de áreas de conservação ambiental, além de sítios destinados ao despejo de resíduos sólidos, num contexto de borda de área de expansão urbana, resulta uma paisagem de transição, uma colcha de retalhos dos tecidos urbano e rural.

Figura 1 - Modelo da estrutura e do desenvolvimento da cidade

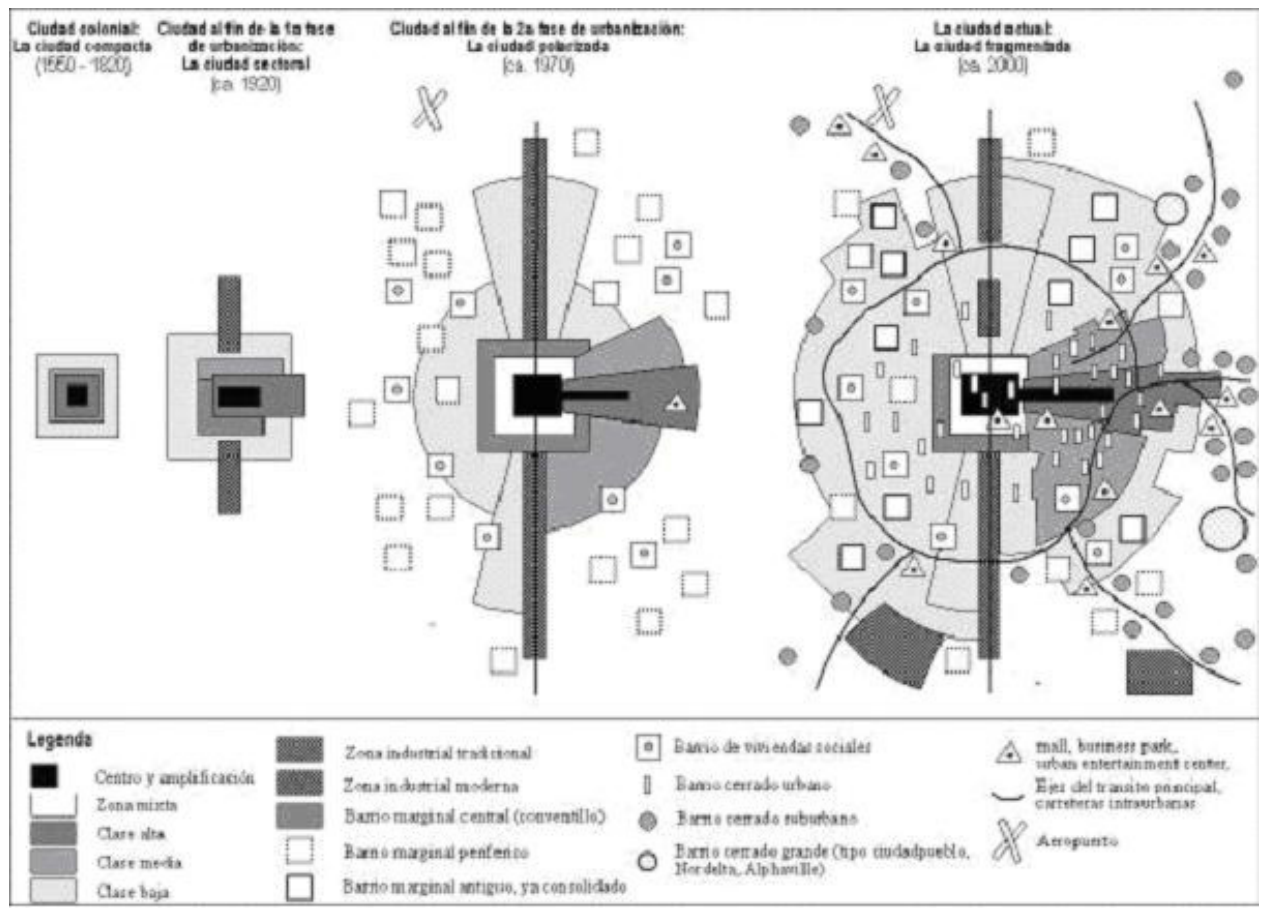

Fonte: BORSDORF (2003, p. 3)

Na figura 1, está posta uma síntese da evolução do arranjo urbano desde a cidade compacta até o modelo da cidade dispersa e fragmentada que está relacionada com o advento da periurbanização. Observando-se o quarto esquema, é possível identificar um grande número de equipamentos urbanos que se projeta para além de uma mancha urbana mais densa. A zona industrial flexível e o condomínio fechado suburbano coexistem com elementos não identificados no esquema, a saber, propriedades agropecuárias, espaços de lazer "verde" etc.

Nesse contexto, a cidade de Jos, Nigéria, serve como um exemplo clássico de imbricação de usos - cultura de hortaliças alternadas com instalações como as da 
universidade local e usos habitacionais urbanos, conforme apontado por Harris et al. (2006). Tais condições são observáveis na figura 2.

Na figura 2, vê-se o limite leste da grande mancha urbana concentrada, próximo à Universidade de Jos. A partir daí, para oeste, passando pela estrutura viária que reforça o espraiamento habitacional, o que se observa é um encadeamento de pequenas propriedades rurais e áreas de moradia de baixa densidade.

Figura 2 - Área periurbana de Jos, Nigéria

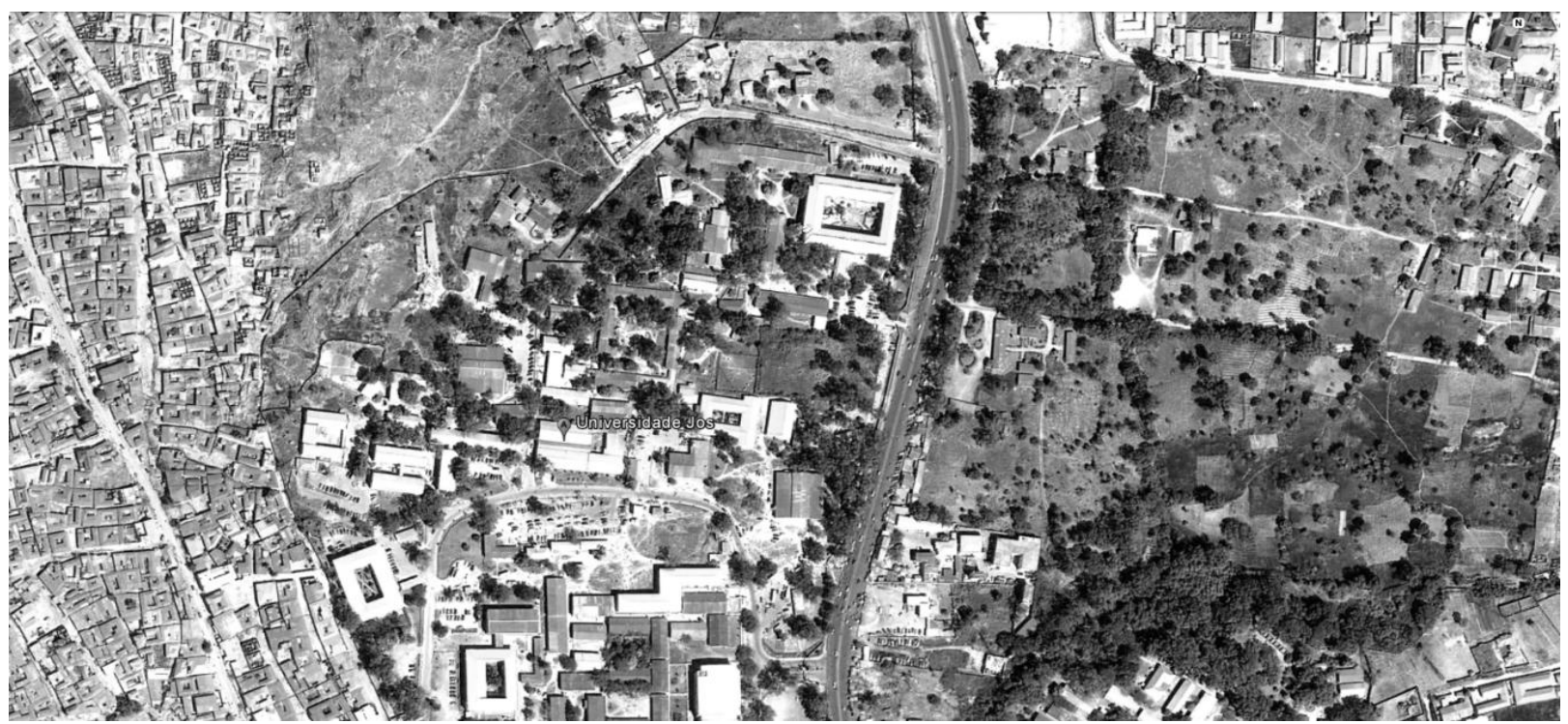

À transição se agrega o sentido de continuum urbano-rural, na acepção de um intervalo entre um elemento, hipotético, absolutamente urbano e outro inequivocamente rural. Nesse intervalo ocorre uma gradação de um elemento para o outro, não somente quanto a aspectos da paisagem, como econômicos e sociais.

Em Macgregor (2006, p. 10) e Bhat (2006, p. 96) verificamos a presença da noção de continuum adaptada à realidade periurbana. Os autores identificam um gradiente periurbano. Nos extremos, comumente, áreas bastante ligadas à cidade, mas já bastante ruralizadas. Nas áreas mais próximas à cidade, a permanência de características rurais, mas maior presença de equipamentos urbanos.

Está na consideração sobre o continuum urbano-rural a chave para se compreender a transicionalidade dos espaços periurbanos, diferenciando-os daquilo que se convencionou chamar de área de expansão urbana. Na área de expansão urbana, espaço destinado para o crescimento da cidade, a transição é vista como o processo de alteração de solo rural para solo urbano, parte da área densamente construída. Sob o processo de periurbanização, no entanto, a transição implica a transformação do espaço de maneira que este tenha permanências rurais diante das mudanças ensejadas na lógica da cidade. A transição periurbana, portanto, é o amálgama urbano-rural tendendo a uma duração maior do que na lógica dos espaços para a expansão urbana.

Os interesses imobiliários são um exemplo de força que garante a duração dessas paisagens mistas, em vez de sua incorporação à mancha tradicional. Carlos (1994, p. 77), 
discorrendo sobre o mercado imobiliário metropolitano, dá um exemplo do poder desse mercado na constituição e resiliência desses espaços, por conta da "venda do verde" , da valorização dos espaços periféricos como "subúrbio jardim".

De fato, é preciso se ter em mente que há na transição periurbana certa transitoriedade. Para Steinberg (2003, p. 2), as manchas periurbanas mais próximas tendem a se unir à cidade principal por "contágio". Trata-se, assim, de um ritmo diferente do processo de incorporação das áreas mais próximas à mancha principal do que era visto há algumas décadas em diversos países.

\section{CONFLITO E OPORTUNIDADE}

Aspectos recorrentes nos textos dos pesquisadores sobre áreas periurbanas são os conflitos próprios dessas áreas, inerentes à fricção de suas diversas formas de ocupação do solo, de sua composição social diversa, bem como de seu papel na indução da distensão do tecido urbano sobre áreas rurais.

Em relação aos conflitos ambientais, Morale et al. (2002) demonstra que o padrão de espraiamento causa um enorme consumo de solo, bem como a manutenção do padrão de mobilidade ao centro e as consequentes altas taxas de consumo de combustíveis.

Em Lisboa, Margarida Pereira (2004) aponta a periurbanização como um dos grandes desafios para a cidade, à medida que o padrão de urbanização de densidades menores teria grandes implicações ambientais e mesmo econômicas, considerando-se que os fragmentos urbanos distantes do núcleo demandam infraestrutura para locomoção, serviços públicos básicos etc.

Prados et al. (2007) apresenta relação entre áreas periurbanas e aumento de risco e vulnerabilidade da população a eventos ambientais extremos. Os autores caracterizam aspectos morfológicos e dinâmicos próprios de áreas periurbanas que ensejariam maior perigo ou vulnerabilidade a eventos extremos.

Apresentam uma série de fricções entre as áreas ocupadas nas franjas periurbanas e as características ambientais adjacentes de forma que aumente a exposição da população às fragilidades ambientais. Mostram que essas áreas, por estarem no limiar entre áreas de distintas jurisdições, costumeiramente se encontram em um limbo regulatório e institucional, de forma que não ocorre planejamento e controle mínimo necessário ao equilíbrio das ocupações (PRADOS et al., 2007).

Rodriguez et al. (2010) aplicam ao caso concreto de Málaga, na Espanha, o quadro relacional exposto em Prados et al. (2007). Em ambos encontra-se uma correlação entre características morfológicas e dinâmicas que, usualmente relacionadas às áreas periurbanas, implicariam um maior risco ambiental de eventos extremos, bem como maior vulnerabilidade das populações periurbanas a tais eventos.

Entre os aspectos comuns às áreas periurbanas ligados ao aumento de risco e vulnerabilidade estão: valorização e adensamento de áreas de risco - encostas sujeitas a 
deslizamentos, vales sujeitos a inundações, etc. -; ausência de planejamento adequado à dinâmica de ocupação esparsa, e a fricção causada pelo contato de diferentes usos.

Também de maneira prática, Douglas (2006) apresenta o resultado da interação de estratégias rurais em contato com espaços urbanos, mostrando que nas áreas periurbanas da Jordânia a agricultura periurbana tem contaminado os aquíferos pelo uso indiscriminado de defensivos agrícolas. No contato próximo com grandes aglomerações, em uma região sujeita a estiagens, o resultado tem sido bastante pior para a população do que se a mesma agricultura estivesse instalada fora dos interstícios das aglomerações urbanas.

Bowyer-Bower (2006) acrescenta que, nas áreas periurbanas de países subdesenvolvidos, uma das principais distinções entre as áreas periurbanas e as demais se encontra justamente no conflito de competência administrativa. A autora considera que, em razão do uso misto da terra, a política que prevalece em certas áreas - ora urbana, ora rural - não dá conta das reais necessidades dos diferentes usos coexistentes.

Para Miranda (2008) os processos de mudanças de atividades desenvolvidas nos imóveis rurais e urbanos, desde a simples mudança de uso até a crescente conversão das terras rurais em urbanas, dificultam o enquadramento dos imóveis e a criação de zonas com atividades uniformes. Assim, no sentido de procurar mitigar as questões concernentes às áreas de transição, apresenta uma série de aplicabilidades dos instrumentos brasileiros de gestão territorial a essas áreas - parcelamento, edificação ou utilização compulsórios; o IPTU progressivo no tempo; a desapropriação com pagamento em títulos; Zonas Especiais de Interesse Social; direito de preempção e o consórcio imobiliário; outorga onerosa do direito de construir; Plano Diretor; transferência do direito de construir; estudo de impacto de vizinhança; regularização fundiária; conferências da cidade; audiências e consultas públicas; EIA-RIMA etc.

Conforme exposto até aqui, os estudos sobre áreas de transição têm dado grande atenção ao aspecto do conflito, quer seja social, econômico, ambiental ou político. É preciso salientar, no entanto, as oportunidades engendradas pelas estruturas e dinâmicas interativas dessas áreas de borda.

Alguns estudos, especialmente versados sobre os casos africanos, têm mostrado como as áreas periurbanas têm servido para o desenvolvimento de estratégias de subsistência por parte de famílias mais pobres. Essas estratégias contam significativamente com a posição das manchas paisagísticas rurais no entremeio de áreas mais adensadas. São os exemplos da agricultura irrigada em tempos de estiagem em Jos, Nigéria, pesquisados por Harris et al. (2006), a maior proximidade com informações de mercado e a possibilidade de eliminação de intermediários na horticultura tanzaniana (LYNCH; POOLE, 2006), o pastoralismo em Yabello, Etiópia (ABERRA, 2006), entre outros.

Obviamente, tais abordagens não se restringem aos países africanos, sendo também encontradas abordagens que enfocam as oportunidades para as estratégias familiares dos pobres em Hubli-Dharwad, Índia, (BHAT, 2006), Anse La Raye, Santa Lúcia, (MYCOO, 2006), Calcutá, Índia, (MUKHERJEE, 2006). 
Alguns autores têm atentado para as áreas periurbanas como receptoras dos diversos rejeitos urbanos e apresentado certas estratégias para a reutilização desses rejeitos como uma oportunidade própria para essas áreas.

Em Calcutá, a aquicultura periurbana tem utilizado matéria orgânica retirada de esgoto previamente tratado para o alimento dos peixes (MUKHERJEE, 2006). ABDULLAH et al. (apud MACGREGOR, 2006) demonstram como os nutrientes do lixo urbano podem ser reciclados a partir de sua aplicação na agricultura periurbana, utilizando um estudo de caso em Kumasi, Gana.

Ainda no sentido das contribuições ambientais oportunizadas pelas áreas de transição, Padilla et al. (2011) mostram que em Alicante, Espanha, as estruturas periurbanas de moradia e o policentrismo do emprego têm diminuído as distâncias na locomoção residência-trabalho, reduzindo, portanto, as emissões de gases dos transportes. Salienta-se, no entanto, que essa situação é bastante diferente da verificada em Santiago do Chile, conforme verificado por Morale et al. (2002). Isso deve, assim, estar ligado à capacidade de policentrismo do emprego em uma proporção equivalente à descentralização das áreas habitacionais.

\section{CONSIDERAÇÕES FINAIS}

As áreas periurbanas são pesquisadas há mais de sessenta anos, tendo surgido nos Estados Unidos a partir do conceito de franjas urbanas. Após a constatação da expansão do processo de periurbanização por países europeus e a sua generalização, atingindo países mais pobres e em desenvolvimento, a partir da nova divisão internacional do trabalho, vê-se que há no presente um momento de crescimento do interesse sobre a temática no Brasil.

Esse conceito, bastante difundido para tratar de realidades muito díspares - o entorno de cidades milionárias no Sudeste asiático, o processo de movimento da alta classe média europeia para subúrbios mais distantes, repletos de amenidades, ou ainda para referir aos arrabaldes empobrecidos de cidades de diversos portes na África - apresenta certos aspectos comuns, aqui sistematizados na transição, intermediação, conflito e oportunidade.

Entendemos que esses quatro elementos são fundamentais, uma espécie de chave interpretativa que se está construindo ao redor do conceito de espaço periurbano. Dessa forma, essa sistematização é uma contribuição para a discussão sobre as áreas, num momento de crescimento da pesquisa, a fim de se estabelecer os fundamentos sobre os quais o conceito é articulado no espaço urbano-regional.

Avalia-se que o uso do conceito de espaço periurbano pode contribuir para o planejamento urbano-regional, tendo ampla referência internacional no assunto, no entanto carecendo de maior aprofundamento e de estudos de caso no Brasil. Para tanto, uma agenda de pesquisa é necessária para a compreensão das especificidades do periurbano no Brasil. Essa agenda pode contar com pesquisas sobre: 
- seus ritmos e vetores de crescimento; os diferentes graus de imbricação de atividades ao longo do espaço periurbano;

- identificação das consequências sociais e ambientais da convivência de atividades urbanas e rurais nas áreas de maior imbricação no espaço periurbano;

- possíveis modelos de ordenamento territorial para as áreas periurbanas que possam levar ao crescimento econômico, ao desenvolvimento social e à proteção ambiental de espaços fragilizados do ponto de vista socioambiental;

- formas de tornar os espaços intersticiais mais atrativos ao desempenho de atividades rurais, em vez de reserva de terra para loteamentos urbanos;

- comparar ritmos de crescimento, níveis de imbricação de usos etc. de áreas periurbanas de diferentes regiões metropolitanas brasileiras, com vista a observar padrões comuns e particularidades regionais;

- efeitos da fragmentação sobre a noção de pertencimento local dos habitantes e na conformação de governança participativa;

- diferenças nos custos de infraestruturas diversas nas áreas urbanas e periurbanas, além do levantamento de possíveis soluções alternativas para as demandas das áreas de densidade média.

Na pesquisa na qual a revisão aqui apresentada conforma parte dos resultados, espera-se que a demarcação - em andamento - das áreas periurbanas da Região Metropolitana de Curitiba contribua com novos olhares sobre as dinâmicas da periurbanização no Brasil.

\section{REFERÊNCIAS}

ABRAMOVAY, R. Funções e medidas da ruralidade no desenvolvimento contemporâneo. Rio de Janeiro: IPEA, 2000. Disponível em: <http://ipea.gov.br/pub/td/2000/td_0702.pdf>. Acesso: em 15 fev. 2012.

ABDULLAH, A. -B. et al. Community-based waste management strategies: peri-urban interface, Kumasi, Ghana. In: MACGREGOR, Duncan et al. The Peri-Urban Interface. Londres: Earthscan, 2006. p. 229-245.

ABERRA, E. Alternative strategies in alternative spaces: livelihoods of pastoralistis in the peri-urban interface of Yabello, Southern Ethiopia. In: MACGREGOR et al. The Peri-Urban Interface. Londres: Earthscan, 2006. p. 116-133.

ADELL, G. Theories and models of the peri-urban interface: a changing conceptual landscape. The Development Planning Unit. Londres: University College London, 1999.

ALLEN, A. Understanding environmental change in the context of rural-urban interactions. In: MACGREGOR, Duncan et al. The Peri-Urban Interface. Londres: Earthscan, 2006. p. 30-43.

BHAT, P. et al. Livelihoods from dairying enterprises for the landless in the peri-urban interface around Hubli-Dharwad, India. In: MACGREGOR, Duncan et al. The Peri-Urban Interface. Londres: Earthscan, 2006. p. 94-103.

BOSDORF, A. Hacia la ciudad fragmentada. Tempranas estructuras segregadas en la ciudad latinoamericana. Scripta Nova. Universidad de Barcelona, v. VII, n. 146, $1^{\circ}$ ago. 2003. Disponível em: <http:/ / www.ub.edu/ geocrit/sn/sn-146(122).htm>. Acesso em: 20 out. 2011.

BOWYER-BOWER, T. A. S. The inevitable illusiveness of sustainability in the peri-urban interface: the case of Harare. In: MACGREGOR, D. et al. The Peri-Urban Interface. Londres: Earthscan, 2006. p. 151-164. 
CARLOS, A. F. A. O meio ambiente urbano e o discurso ecológico. In: Revista do Departamento de Geografia da USP, n. 8, São Paulo: Faculdade de Filosofia, Letras e Ciências Humanas, 1994.

CORREAA, R. L. A periferia urbana. GEOSUL: Revista do departamento de Geociências (UFSC), ano I, n. 2, 1986. Disponível em: <http://www.periodicos.ufsc.br/index.php/geosul/issue/view/1215>. Acesso em: 10 maio 2012.

DOUGLAS, I. Peri-urban ecosystems and societies: transitional zones and contrasting values. In: MACGREGOR, D.; SIMON, D.; THOMPSON, D. The Peri-Urban Interface. Londres: Earthscan, 2006. p. 18-29.

HARRIS, F. et al. The Environmental and social impacts of peri-urban irrigate vegetable production around Jos, Nigeria. In: MACGREGOR, Duncan et al. The Peri-Urban Interface. Londres: Earthscan, 2006. p. 59-73.

INSEE. La croissance périurbaine depuis 45 ans. INSEE Première. Paris. 2009. Disponível em: <http:// www.insee.fr/fr/themes/document.asp?ref_id=ip1240>. Acesso em: 10 nov. 2011.

JUILLARD, É. Brasil e Europa. Dois tipos de organização do espaço Periurbano. Boletim Baiano de Geografia, v. 1, 1961. Apud CORRÊA, R.L. A periferia urbana. Geosul, Revista do departamento de Geociências (UFSC), ano I, n. 2, 1986. Disponível em: <http:/ /www.periodicos.ufsc.br/index.php/geosul/ issue/view/1215>. Acesso em: 10 maio 2012.

LABORE. Seminário Internacional "A Expansão da Metrópole para além das Fronteiras da sua Região: Continuidade ou Ruptura?". Caderno de Resumos. Rio de Janeiro, 2009.

LYNCH, K.; POOLE, N. Horticulture and market information at the peri-urban interface: agricultural marketing in Tanzania. In: MACGREGOR, D.; SIMON, D.; THOMPSON, D. The Peri-Urban Interface. Londres: Earthscan, 2006. p. 74-93.

MACGREGOR, D. et al. Contemporary perspectives on the peri-urban zones of cities in developing contries. In: __ The Peri-Urban Interface. Londres: Earthscan, 2006. p. 3-17.

MIRANDA, L. I. B. de. Produção do espaço e planejamento em áreas de transição rural-urbana: o caso da Região Metropolitana do Recife - PE. Tese de Arquitetura (Programa de Pós-Graduação em Desenvolvimento Urbano) Universidade de Pernambuco, 2008, 312 p.

MORALE, S. et al. Impacto socioespacial de las migraciones intraurbanas en entidades de centro y de nuevas periferias del Gran Santiago. EURE. Santiago, v. 28, n. 85, dez. 2002. Disponível em: <http://www. scielo.cl/scielo.php?script=sci_arttext\&pid=S025071612002008500009\&lng=es\&nrm=iso>. Acesso em: 14 out. 2011.

MUKHERJEE, M. Wasted-fed fisheries in peri-urban kolkata. In: MACGREGOR, D. et al. The Peri-Urban Interface. Londres: Earthscan, 2006. p. 104-115.

MYCOO, M. Sustainable livelihoods in the peri-urban interface: Anse La Raye, St Lucia. In: MACGREGOR, D. et al. The Peri-Urban Interface. Londres: Earthscan, 2006. p. 134-148.

PADILLA, Armando Ortuño et al. Aproximación a la génesis de la contribución de la densidad en la noción de "ciudad compacta". EURE, v. 37, n. 112, set. 2011. p. 23-41.

PEREIRA, M. et al. Modelos de ordenamento em confronto na área metropolitana de Lisboa: cidade alargada ou recentragem metropolitana? Cadernos Metrópole, EDUC, Ed. da Pontifícia Univ. Católica deSão Paulo, Brasil, 2008, p. 107-123. n. 20, $2^{\circ}$ semestre, Disponível em: <http://web.observatoriodasmetropoles. net/>. Acesso em: 19 ago. 2009.

PEREIRA, M. As metamorfoses da cidade dispersa. GEOINOVA. Lisboa. FESH, n. 10, 2004. p. 129-142.

PIORR, A. et al. Peri-urbanisation in europe towards European policies to sustain urban-rural futures. Relatório de síntese. Plurel. Londres, 2011. Disponível em: <ww.plurel.net/images/Peri_Urbanisation_in_ Europe_printversion.pdf>. Acesso em: 12 jan. 2012.

PRADOS, F.C. et al. Particularidades de la generación del riesgo en espacios periurbanos. Revista Baetica. Faculdade de Filosofía y Letras da Universidad de Málaga, 2007. p. 145-153.

PRYOR, R.J. Defining the rural-urban fringes. Social Forces, v. 47, n, 2. Disponível em: <www.jstor.org/ stable/2575150>. University of North Carolina, p. 202-215, dez. 1968. 
RANDOLPH, R. Distribuição espacial do crescimento populacional dentro e fora da Região Metropolitana do Rio de Janeiro. Revista de Economia Fluminense, v. 3, p. 28-33, 2007.

RODRÍGUEZ, M. M. et al. Patron Territorial y conformación del riesgo en espacios periurbanos. El caso de la periferia este de la Ciudad de Málaga. Scripta Nova. Universidad de Barcelona, v. XIV, n. 329, 10 jul. 2010. Disponível em: <http://www.ub.edu/geocrit/sn/sn-329.htm>. Acesso em: 20 de outubro de 2011.

SANTOS, M. A urbanização brasileira. São Paulo. Hucitec. 1993.

SILVA, J. G. Velhos e novos mitos do rural brasileiro. Revista Instituto de Estudos Avançados da Universidade de São Paulo. IEA. São Paulo, n. 43, p. 37-50, 2001. Disponível em: <http:/ /www.scielo.br/ pdf/ea/v15n43/v15n43a05.pdf>. Acesso: em 10 dez. 2011.

SPOSITO, M. E. B.; WHITACKER, Arthur M.(Orgs.). Cidade e Campo: relações e contradições entre urbano e rural. São Paulo: Expressão Popular, 2006.

STEINBERG, J. La Périurbanisation en France (1998-2002). Lisboa, 2003. GEOINOVA, FESH, n. 7, p. 75-85.

VALE, A. R. do. Expansão urbana e plurifuncionalidade no espaço periurbano do município de Araraquara (SP). Rio Claro. Tese de Geografia. 2005. 211 p.

VEIGA, J. E. da. Cidades imaginárias: o Brasil é menos urbano do que se calcula. Campinas - São Paulo: Autores Associados, 2002.

Recebido em 13/10/2012

Aceito para publicação em 22/10/2013 